\title{
Knowledge of Stroke Risk Factors and Signs in Parakou, a Northern City of Benin in West Africa
}

\author{
Mendinatou Agbetou Houessou ${ }^{a, b}$ Hospice Hountadab \\ Bertrand Yahouédéou $^{b}$ Blaise Choki ${ }^{b}$ Oyéné Kossia, ${ }^{a}$ Thierry Adoukonou ${ }^{a, b, c}$ \\ aDepartment of Neurology, University of Parakou, Parakou, Benin; ${ }^{b}$ Clinic of Neurology, University Teaching \\ Hospital of Parakou, Parakou, Benin; CUMR-1094 INSERM, University of Limoges, CHU Limoges, UMR 1094, Tropical \\ Neuroepidemiology, Institute of Epidemiology and Tropical Neurology, GEIST, Limoges, France
}

\section{Keywords \\ Stroke $\cdot$ Knowledge $\cdot$ Parakou $\cdot$ Benin}

\begin{abstract}
Introduction: We aimed to determine knowledge of stroke risk factors and signs in an urban population of northern Benin. Methods: A door-to-door purposeful sampling survey was conducted in resident population (age $\geq 15$ years) of the district of Titirou in the city of Parakou $(N=255,478)$ in Benin between March 15 and July 15, 2016. In-person interviews were conducted with data collection on structured questionnaires with close and open questions, according to standard definitions. Multivariable logistic regression was used to assess predictors of good knowledge, defined by provision of a correct response in pre-defined set of questions on stroke risk factors and warning signs. Results: Of 4,671 participants (mean age $27.7 \pm 12.9$ years; females $50.6 \%$ ), only 404 (8.6\%) knew at least 1 stroke risk factor. Knowledge level of stroke risk factors (odds ratio, 95\% confidence interval) was related to age $(1.37,1.27-1.48)$, level of education (2.54, 1.73-3.72), and family history of stroke (3.01, 2.08-4.26). Only $230(4.9 \%)$ were able to cite at least 1 stroke symptom, and this knowledge was great with increasing age (1.04, 1.02-
\end{abstract}

1.06), family $(3.63,2.41-5.49)$ and personal history of stroke (3.71, 1.86-7.42), and high level of education (4.35, 2.687.07). Conclusion: Knowledge of stroke risk factors and signs is low in northern Benin. Greater public education and awareness campaigns are required to address the burden of stroke.

(c) 2021 S. Karger AG, Basel

\section{Introduction}

There is a heavy burden of stroke in sub-Saharan Africa, where incidence and prevalence range from 15 to 159 and 15 to 815 , per 100,000 persons-years, respectively [1-3]. In the western country of Benin, several studies have highlighted the high rates of stroke [4-8] and its consequences in terms of disability, depression, epilepsy, and restricted social participation [6-8]. Prevention is key to reducing the burden of stroke, with joint efforts required at individual and community levels, but low levels of stroke awareness have been highlighted in many populations [9-12], particularly in high-risk individuals [13] and regions of sub-Saharan Africa [14-17]. As an earlier study has shown low stroke knowledge in the pop-

$\begin{aligned} & \text { karger@karger.com } \\ & \text { www.karger.com/ced }\end{aligned}$
Karger ${ }^{\prime /}$

Mendinatou Agbetou Houessou

Department of Neurology, Teaching Hospital of Parakou

University of Parakou

Parakou 03BP 10 (Benin)

mendiagbetou@yahoo.fr 
ulation of Cotonou, the largest city and economic centre in the south of Benin [18], we undertook a survey to provide such information for the population of Parakou in the north.

\section{Methods}

\section{Study Design and Population}

A door-to-door cross-sectional survey was undertaken among the inhabitants (age $\geq 15$ years, resident $\geq 6$ months) of the district of Titirou in Parakou, a northern city located approximately 425 $\mathrm{km}$ from Cotonou in Benin, between March 15 and July 15, 2016. Parakou had population of 255,478 inhabitants (female $50.2 \%$ ) in 2013, with a density of 577 inhabitants $/ \mathrm{km}^{2}$, and is divided into 3 districts of 41 neighbourhoods and villages. Titirou, the second most populated neighbourhood spread across 7 municipality subdivisions, had a population of 25,530 inhabitants according to the Fourth General Census of Population and Housing in 2013 [19]. Data were collected through personal interview using a standardized questionnaire and divided into 2 main parts: socio-demographic data and stroke knowledge with a combination of open and closed questions.

\section{Variables}

Data were obtained on the stroke risk factors that included hypertension, diabetes mellitus, smoking, obesity, dyslipidaemia, alcoholism, heart disease, previous stroke or transient ischaemic attack, migraine, hormonal contraception, low consumption of fruits and vegetables, low physical inactivity, and family history of vascular disease, according to definitions of the World Health Organization (WHO) Stepwise survey approach [20]. Knowledge of stroke symptoms and signs were from the National Institute of Neurological Disorders and Stroke (NINDS) [21] and included sudden weakness or numbness of the face, arm, or leg especially on 1 side of the body; sudden confusion or difficulty in speaking or understanding speech; sudden visual impairment in 1 or both eyes; sudden difficulty in walking; dizziness, or loss of balance or coordination; and sudden severe headache with no known cause. Knowledge level was defined as "good" if subjects evoked a spontaneous a correct response to at least one of the variables related to knowledge and warning signs.

Exposure variables were socio-demographic (age, sex, occupation, highest level of education [primary, secondary, tertiary], religion, and marital status) and medical history (hypertension, diabetes mellitus, smoking, low consumption of fruits and vegetables, physical inactivity, alcoholism, previous stroke or transient ischaemic attack, family history of vascular disease, and obesity). Hypertension was defined as systolic blood pressure $\geq 140 \mathrm{~mm} \mathrm{Hg}$ or diastolic blood pressure $\geq 90 \mathrm{~mm} \mathrm{Hg}$, or previous history of hypertension or use of antihypertensive medication. Diabetes mellitus was defined as fasting plasma glucose $\geq 1.26 \mathrm{~g} / \mathrm{L}$, previous history of diabetes mellitus, or use of hypoglycaemic medication. Smoking was defined as any smoking ( $\geq 1$ cigarette/day) in the last 5 years. Alcohol consumption was any alcohol at least once weekly in the last year. Cardiac disease referred to self-reported ischaemic heart disease, cardiomyopathy, heart failure, or arrhythmia. Low consumption of fruits and vegetables was $<5$ of either per day. Family history of vascular disease or hypertension was by self-report. Obe-

Knowledge of Stroke in Northern Benin
Table 1. Distribution of the participants from each subdivision of Parakou in 2016

\begin{tabular}{lccc}
\hline Titirou subdivision & $\begin{array}{l}\text { Population } \\
\text { target }\end{array}$ & $\begin{array}{l}\text { Planned } \\
\text { number* }\end{array}$ & $\begin{array}{l}\text { Investigated } \\
\text { number }\end{array}$ \\
\hline Borarou & 461 & 166 & 170 \\
Dama N'kparou & 292 & 105 & 110 \\
Gounin & 848 & 305 & 310 \\
Mondouro & 538 & 194 & 200 \\
Titirou centre & 9,328 & 9,358 & 3,396 \\
Tobou N'kparou & 512 & 184 & 185 \\
Toukossari & 837 & 301 & 300 \\
\hline Total & 12,816 & 4,613 & 4,671 \\
\hline
\end{tabular}

* In proportion to the size of each subdistrict.

sity was defined according to BMI $\geq 30 \mathrm{~kg} / \mathrm{m}^{2}$, based on self-reported height and weight.

\section{Statistical Analysis}

Based on a previous study in Benin [18], a sample size of 4,567 subjects was estimated to provide a prevalence of good stroke knowledge of $(14.1 \%)$ with a precision of 0.015 (alpha $=0.05)$. After dividing the population of Titirou by the proportional size of each subdistrict, field investigators randomly determined the direction from a central area to consecutively interview all residents meeting the inclusion criteria. If they were unable to achieve the desired number, they returned to the centre to repeat the operation in another direction to achieve the expected number. Table 1 outlines flow of participants in each subdistrict.

\section{Data Analysis}

Quantitative variables were expressed as means ( \pm standard deviation) for those normally distributed and qualitative variables expressed in proportion with $95 \%$ confidence intervals (CI). Proportions were compared with the $\chi^{2}$ or Fisher's exact test and comparison of means with the Student test. Multivariable logistic regression was used to determine the predictors of good knowledge of stroke risks factors and warning signs, with significant variables ( $p$ value $<0.05$ ) simultaneously introduced stepwise into models, and expressed as odds ratios (OR) and 95\% CI. All analyses were undertaken with Stata version 16 software (Stata Press, 4905 Lakeway Drive, College Station, TX, USA).

\section{Results}

There were 4,671 participants of whom 2,365 (50.6\%) were female with a mean age $27.7( \pm 12.9)$ years and range 15-99 years (Table 2). Over half (55.3\%) had at least a secondary level of education and $40.0 \%$ were students.

Overall, 3,588 (76.8\%) had never heard about stroke, and only $402(8.6 \%)$ could identify at least 1 vascular risk 
Table 2. Knowledge of stroke risk factors in Parakou in 2016

\begin{tabular}{|c|c|c|c|c|c|c|c|}
\hline & \multirow[t]{2}{*}{$N(\%)$} & \multicolumn{2}{|c|}{ Knowledge of $\geq 1$ risk factor } & \multirow[t]{2}{*}{ OR $[95 \% \mathrm{CI}]$} & \multirow[t]{2}{*}{$p$ value } & \multirow[t]{2}{*}{ aOR $[95 \% \mathrm{CI}]$} & \multirow[t]{2}{*}{$p$ value } \\
\hline & & $\begin{array}{l}\text { yes } \\
N(\%)\end{array}$ & $\begin{array}{l}\text { no } \\
N(\%)\end{array}$ & & & & \\
\hline \multicolumn{8}{|l|}{$\operatorname{Sex}$} \\
\hline Male & $2,306(49.4)$ & $210(9.1)$ & $2,096(90.9)$ & 1 & 0.149 & & \\
\hline Female & $2,365(50.6)$ & $194(8.2)$ & $2,171(91.8)$ & 0.89 [0.73-1.09] & & & \\
\hline Age, years & $27.7 \pm 12.9$ & $33.1 \pm 13.8$ & $27.2 \pm 12.7$ & & 0.0001 & $1.37[1.27-1.48]^{*}$ & $<0.001$ \\
\hline \multicolumn{8}{|l|}{ Age-group } \\
\hline $15-24$ years & $2,475(53.0)$ & $130(5.2)$ & $2,345(94.8)$ & 1 & 0.0001 & 1 & \\
\hline $25-34$ years & $1,169(25.0)$ & $133(11.4)$ & $1,036(88.6)$ & $2.31[1.80-2.98]$ & & $2.22[1.70-2.90]$ & \\
\hline $35-44$ years & $481(10.3)$ & $61(12.7)$ & $420(87.3)$ & $2.62[1.90-3.61]$ & & $2.60[1.84-3.67]$ & \\
\hline $45-54$ years & $261(5.6)$ & $40(15.3)$ & $221(94.7)$ & $3.26[2.23-4.78]$ & & $3.25[2.17-4.87]$ & \\
\hline $55-64$ years & $184(3.9)$ & $27(14.7)$ & $157(85.3)$ & $3.10[1.99-4.84]$ & & $3.33[2.09-5.33]$ & \\
\hline$\geq 65$ years & $101(2.2)$ & $13(12.9)$ & $88(87.1)$ & $2.66[1.45-4.96]$ & & $3.09[1.67-5.73]$ & \\
\hline \multicolumn{8}{|l|}{ Religion } \\
\hline Muslim & $2,042(43.7)$ & $235(9.1)$ & 2,807 (90.9) & $1.47[0.45-4.84]$ & 0.690 & & \\
\hline Christian & $1,591(55.5)$ & $166(8.1)$ & 2,425 (91.9) & $0.78[0.24-2.55]$ & & & \\
\hline Other & $37(0.8)$ & $3(8.6)$ & $34(91.4)$ & 1 & & & \\
\hline \multicolumn{8}{|l|}{ Level of education } \\
\hline None & 807 (17.3) & $69(8.6)$ & $738(91.4)$ & 1 & $<0.001$ & 1 & $<0.001$ \\
\hline Primary & 875 (18.7) & $95(10.9)$ & $780(89.1)$ & $1.30[0.94-1.80]$ & & $1.36[0.98-1.89]$ & \\
\hline Secondary & $2,581(55.3)$ & $175(6.8)$ & $2,406(93.2)$ & $0.78[0.58-1.04]$ & & $1.25[0.91-1.71]$ & \\
\hline High (university) & $408(8.7)$ & $65(15.9)$ & $343(84.1)$ & $2.03[1.41-2.91]$ & & $2.54[1.73-3.72]$ & \\
\hline \multicolumn{8}{|l|}{ Marital status } \\
\hline Couple & $2,022(43.3)$ & $236(11.7)$ & $2,786(88.3)$ & $1.95[1.59-2.40]$ & 0.0001 & - & \\
\hline Single & $2,649(56.7)$ & $168(6.3)$ & $1,481(93.7)$ & & & & \\
\hline \multicolumn{8}{|c|}{ History of hypertension } \\
\hline Yes & $331(7.1)$ & $43(13.0)$ & $288(87.0)$ & $1.65[1.17-2.31]$ & 0.004 & - & \\
\hline No & $4,340(92.9)$ & $361(8.3)$ & $4,979(91.7)$ & 1 & & & \\
\hline \multicolumn{8}{|l|}{$B M I$} \\
\hline Underweight & $324(6.9)$ & $18(5.6)$ & $306(94.4)$ & 1 & $<0.001$ & - & \\
\hline Normal & $3,043(65.1)$ & $229(7.5)$ & $3,814(92.5)$ & $1.38[0.84-2.27]$ & & & \\
\hline Overweight & $908(8.5)$ & $60(15.2)$ & $848(84.8)$ & $1.20[0.70-2.07]$ & & & \\
\hline Obesity & $396(19.4)$ & $97(10.7)$ & $299(89.3)$ & $5.51[3.25-9.25]$ & & & \\
\hline \multicolumn{8}{|l|}{ History of stroke } \\
\hline Yes & $54(1.2)$ & $13(24.1)$ & $41(75.9)$ & $3.43[1.82-6.45]$ & 0.001 & - & \\
\hline No & $4,617(98.8)$ & $391(8.5)$ & $4,226(91.5)$ & 1 & & & \\
\hline \multicolumn{8}{|c|}{ Family history of stroke } \\
\hline Yes & $201(4.3)$ & $47(23.4)$ & $154(76.6)$ & 3.52 [2.49-4.95] & $<0.001$ & $3.01[2.08-4.26]$ & $<0.001$ \\
\hline No & $4,470(95.7)$ & $357(8.0)$ & $4,113(92.0)$ & 1 & & 1 & \\
\hline \multicolumn{8}{|l|}{ Tobacco use } \\
\hline Yes & $161(3.4)$ & $19(11.8)$ & $142(87.2)$ & $1.1[0.99-1.04]$ & 0.1 & - & \\
\hline No & $4,506(96.6)$ & $385(8.5)$ & $4,121(91.5)$ & 1 & & & \\
\hline \multicolumn{8}{|l|}{ Diabetes mellitus } \\
\hline Yes & $59(1.3)$ & $7(11.9)$ & $52(88.1)$ & $1.13[0.64-3.16]$ & 0.247 & - & \\
\hline No & $4,604(98.7)$ & $397(8.6)$ & 4,207 (91.4) & 1 & & & \\
\hline
\end{tabular}


Table 3. Knowledge of stroke signs in Parakou 2016

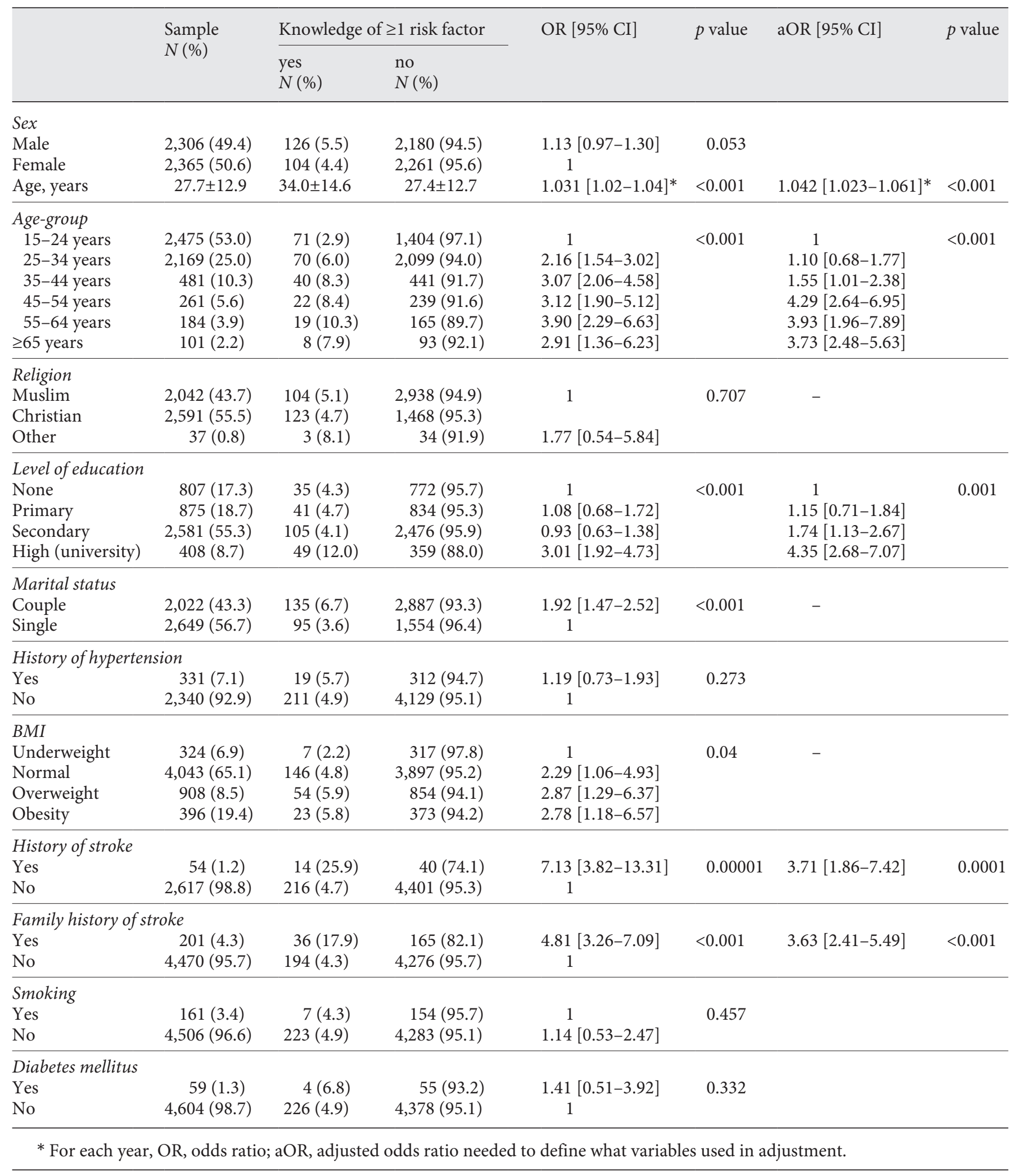


factor. Higher knowledge was found in married people $(11.7 \%)$ and those older, particularly in the age-groups 45-54 (15.5\%) and 55-64 (14.7\%) years. In univariate analysis, age, level of education, marital status, history of hypertension, BMI, history of stroke, and family history of stroke, were associated with good knowledge of stroke risk factors (Table 2). In multivariate analysis, only age (per year, OR 1.37, 95\% CI 1.27-1.48), high level of education (OR 2.54, 95\% CI 1.73-3.72), and family history of stroke (OR 3.01, 95\% CI 2.08-4.26) were associated to knowledge of stroke risk factors (Table 2).

Only 230 participants (4.9\%) were able to cite at least 1 stroke symptom. Knowledge of stroke signs was better among males, subjects aged 55-64 years, and in those with vascular risk factors of obesity, diabetes, family and personal history of stroke (Table 3). In univariate analysis, age, level of education, marital status, BMI, history of stroke, and family history of stroke, were associated with good knowledge of stroke signs. For multivariate analysis, though, only age (per year, OR 1.04, 95\% CI 1.02-1.06), high level of education (OR 4.35, 95\% CI 2.68-7.07), personal history of stroke (OR 3.71, 95\% CI 1.86-7.42), and family history of stroke (OR 3.63, 95\% CI 2.41-5.49) remained significant (Table 3 ).

\section{Discussion}

In our survey of the population of Parakou, more than three-quarters of participants had no knowledge of stroke, with poor awareness of risk factors and signs, and the organ system affected, as shown elsewhere [18]. Although participants in our study were relatively young, potentially reflecting sampling bias, the demographic characteristics were similar to census data for Titirou [19]. Taken together with the earlier study [18], there is clearly a poor level of stroke awareness which likely compromises both prevention and treatment efforts in Benin.

While low levels of stroke knowledge have been reported in Egypt (35.7\%) and Uganda (18\%) [15, 17], this improved after public awareness campaigns involving media or social networks [22]. In our study, knowledge of stroke risk factors was lower than in Cotonou where over 1 third were able to rank hypertension as the most important risk factor [18], but it was higher in those with established risk factors as shown in some $[23,24]$ but not all [25] countries elsewhere. Although higher education, increasing age, and personal and family history of stroke have been associated with better knowledge [10,25], several studies have shown no correlation of age and knowl- edge of stroke signs $[14,25]$ despite older people being more aware of their health, risk factors, and age-related diseases. The relation of stroke knowledge and higher education is well established $[14,25]$, where access to new information through modern technologies, including social networks, can maintain their knowledge about stroke and its treatment.

Strengths of our study were use of door-to-door population-based sampling, and standard definitions of vascular risk factors and signs, to reduce selection and information bias. However, there is the likelihood of some healthy participation bias and imprecision in the estimates through use of both open and closed questions.

In summary, our population-based survey in the northern part of Benin has reinforced considerable gaps in the knowledge of stroke risk factors and signs in this country. There is an urgent need for action and awareness campaigns to increase community awareness of stroke as part of various public health strategies to reduce the burden of stroke.

\section{Statement of Ethics}

Each participant gave oral informed consent before inclusion. The approval of the local Ethical Committee of Biomedical Research of the University of Parakou was obtained (Reference: 029/ CLERB-UP/P/SP/R/SA). The confidentiality of the data was respected.

\section{Conflict of Interest Statement}

The authors declare no conflict interest.

\section{Funding Sources}

No funding for this research.

\section{Author Contributions}

M. Agbetou was involved in acquisition of data, interpreted the data, and drafted the manuscript for intellectual content; H. Hountada and B. Yahouédéou were involved in acquisition of data; B. Choki and O. Kossi interpreted the data; T. Adoukonou was involved in design and conceptualization of the study and final approval of the version to be published.
Agbetou Houessou/Hountada/ Yahouédéou/Choki/Kossi/Adoukonou 


\section{References}

1 Sagui E. [Stroke in sub-Saharan Africa]. Med Trop. 2007;67(6):596-600.

2 Ezejimofor MC, Chen YF, Kandala NB, Ezejimofor BC, Ezeabasili AC, Stranges S, et al. Stroke survivors in low- and middle-income countries: a meta-analysis of prevalence and secular trends. J Neurol Sci. 2016;364:68-76.

3 Adeloye D. An estimate of the incidence and prevalence of stroke in africa: a systematic review and meta-analysis. PLoS One. 2014;9(6): e100724.

4 Cossi MJ, Gobron C, Preux PM, Niama D, Chabriat H, Houinato D. Stroke: prevalence and disability in Cotonou, Benin. Cerebrovasc Dis. 2012;33(2):166-72.

5 Adoukonou T, Yahouédéou B, Agbétou M, Hountada H, Choki B, Kossi O, et al. Prevalence of stroke survivors in Parakou in northern Benin: a door-to-door community survey, Rev Neurol. 2020 Dec;176(10):839-45.

6 Adoukonou T, Accrombessi D, Agbétou M, Houinato D. Incidence of post-stroke depression in Parakou in 2014. Geriatr Psychol Neuropsychiatr Vieil. 2019;17(1):107-12.

7 Adoukonou T, Accrombessi D, Agbetou M, Houinato D. Incidence of epilepsy after cerebrovascular accident in Parakou in 2014. Pan Afr Med J. 2019;32(69):1-8.

8 Adoukonou TA, Kossi O, Yamadjako D, Agbétou $\mathrm{M}$. Restrictions de participation à la vie sociale après un accident vasculaire cérébral chez les sujets âgés au Bénin. NPG. 2018; 18(105):140-8.

9 Croquelois A, Bogousslavsky J. Risk awareness and knowledge of patients with stroke: results of a questionnaire survey 3 months after stroke. J Neurol Neurosurg Psychiatry. 2006;77(6):726-8.
10 Wahab KW, Okokhere PO, Ugheoke AJ, Oziegbe O, Asalu AF, Salami TA. Awareness of warning signs among suburban Nigerians at high risk for stroke is poor: a cross-sectional study. BMC Neurol. 2008;8(1):18.

11 Neau JP, Ingrand P, Godeneche G. Awareness within the French population concerning stroke signs, symptoms, and risk factors. Clin Neurol Neurosurg. 2009;111(8):659-64.

12 Aldebasi KA, Alamri NM, Alqahtani AM. Knowledge, attitude and practice towards stroke risk factors and warning symptoms in Saudi Arabia, 2017. Egypt J Hosp Med. 2017; 69(3):2082-7.

13 Lambert C, Vinson S, Shofer F, Brice J. The relationship between knowledge and risk for heart attack and stroke. J Stroke Cerebrovasc Dis. 2013;22(7):996-1001.

14 Chukwudelunzu FE, Okwu-Delunzu VU, Dzissah J. Knowledge of stroke signs and symptoms among residents in a rural south eastern Nigerian community. J Stroke Cerebrovasc Dis. 2018;27(11):3306-10.

15 Farrag MA, Oraby MI, Ghali AA, Ragab OA, Nasreldein A, Shehata GA, et al. Public stroke knowledge, awareness, and response to acute stroke: multi-center study from 4 Egyptian governorates. J Neurol Sci. 2018;384:46-9.

16 Hertz JT, Madut DB, William G, Maro VP, Crump JA, Rubach MP. Perceptions of stroke and associated health-care-seeking behavior in northern Tanzania: a community-based study. Neuroepidemiology. 2019;53(1-2):417.

17 Kaddumukasa M, Kayima J, Kaddumukasa MN, Ddumba E, Mugenyi L, Pundik S, et al. Knowledge, attitudes and perceptions of stroke: a cross-sectional survey in rural and urban Uganda. BMC Res Notes. 2015;8(1): 819.
18 Cossi MJ, Preux PM, Chabriat H, Gobron C, Houinato D. Knowledge of stroke among an urban population in Cotonou (Benin). Neuroepidemiology. 2012;38(3):172-8.

19 Institut national de la statistique et de l'analyse économique. Résultats provisoires RGPH4. Cotonou, Bénin: INSAE-Bénin; 2013. Vol. 7.

20 Organisation mondiale de la Sante. Le Manuel de Surveillance STEPS de l'OMS: l'approche STEPWISE de l'OMS pour la surveillance des facteurs de risque des maladies chroniques Suisse. Geneve: OMS; 2005.

21 NINDS: Know stroke. Know the signs. Act in time. NIH Publication N¹3-4872 July 2013.

22 Quah JL, Yap S, Cheah SO, Ng YY, Goh ES, Doctor N, et al. Knowledge of Signs and symptoms of heart attack and stroke among Singapore residents. BioMed Res Int. 2014; 2014:572425-8.

23 Donkor ES, Owolabi MO, Bampoh P, Aspelund T, Gudnason V. Community awareness of stroke in Accra, Ghana. BMC Public Health. 2014;14:196.

24 Owolabi M, Akarolo-Anthony S, Akinyemi R, Arnett D, Gebregziabher M, Jenkins C, et al. The burden of stroke in Africa: a glance at the present and a glimpse into the future: review article. Cardiovasc J Afr. 2015;26(2):S27-38.

25 Kamran S, Bener AB, Deleu D, Khoja W, Jumma M, Al Shubali A, et al. The level of awareness of stroke risk factors and symptoms in the Gulf Cooperation Council Countries: Gulf Cooperation Council Stroke Awareness Study. Neuroepidemiology. 2007;29(3-4): 235-42. 